\title{
TRAGÉDIA, COMÉDIA, ROMANCE DE FORMAÇÃO
}

TRAGEDY, COMEDY, NOVEL OF FORMATION

\author{
Kelvin Falcão Klein \\ Universidade Federal do Estado do Rio de Janeiro \\ Rio de Janeiro, RJ - Brasil \\ ORCID 0000-0002-8997-1174
}

\section{Resumo}

Este trabalho parte de um ensaio de Giorgio Agamben dedicado a Dante e à distinção entre comédia e tragédia. Aproveitando certas indicaçóes de Agamben, o trabalho busca reconfigurar a questão do atravessamento entre trágico e cômico, tendo como ponto de partida as teorias acerca do Bildungsroman, o romance de formação, e da heterogeneidade do discurso romanesco de forma ampla. Por fim, é realizada uma aproximaçáo entre Marcel Proust e Franz Kafka (a partir de Walter Benjamin e Franco Rella), apresentando a hipótese de que, seguindo a reconfiguração do contato entre trágico e cômico, o discurso romanesco abarca também uma revisão das categorias de tempo e sujeito.

Palavras-chave: tragédia; comédia; romance de formação; tempo; sujeito.

\section{Abstract}

This work is partly based on an essay by Giorgio Agamben devoted to Dante and the distinction between comedy and tragedy. Making use of some of Agamben's notions, this paper seeks to reconfigure the issue of the tragic-comic intersection, drawing on the theories about the Bildungsroman, the novel of formation, and the heterogeneity of the novelistic discourse in a wider sense. Finally, a parallel is drawn between Marcel Proust and Franz Kafka (with Walter Benjamin and Franco Rella), putting forward the hypothesis that, following the reconfiguration of the contact between tragic and comic, novelistic

\section{Resumen}

Este trabajo parte inicialmente de un ensayo de Giorgio Agamben dedicado a Dante y la distinción entre comedia y tragedia. Haciendo uso de ciertas indicaciones de Agamben, el trabajo busca reconfigurar la cuestión del atravesamiento entre lo trágico y lo cómico teniendo como punto de partida las teorías acerca del Bildungsroman, la novela de formación, y la heterogeneidad del discurso novelesco de forma amplia. Por último, se realiza una aproximación entre Marcel Proust y Franz Kafka (a partir de Walter Benjamin y Franco Rella), presentando la hipótesis de que, siguiendo la reconfiguración del 
discourse also includes a revision of the categories of time and subject.

Keywords: tragedy; comedy; novel of education; time; subject. contacto entre lo trágico y lo cómico, el discurso novelesco abarca también una revisión de las categorías de tiempo y sujeto.

Palavras claves: tragedia; comedia; novela de formación; tiempo; sujeto.

\section{Tragédia e comédia}

No ensaio que abre seu livro Categorias italianas ${ }^{1}$, intitulado simplesmente Comédia, Giorgio Agamben faz um inventário das hipóteses da crítica especializada em Dante e suas tentativas de definição das razóes que levam o autor italiano a escolher o título final de sua obra. "O privilégio conferido ao gênero cômico, que não possui nada de homólogo nem nas fontes medievais nem naquelas tardo-antigas", escreve Agamben, "pressupóe por parte de Dante a intenção de um investimento semântico no termo 'comédia', cuja mira, por

1 Em todos os ensaios reunidos em Categorias italianas (bem como em inúmeros outros momentos de sua obra), um livro que, é importante lembrar, reúne textos que abrangem um período de produção que vai de 1978 a 2007, Agamben propóe reposicionamentos de temas, conceitos e noçôes do Renascimento, da Idade Média e da Antiguidade, com o intuito de reconfigurar o debate sobre o moderno. Uma leitura rápida já nos mostra uma reativação da "tese medieval dos vários sentidos das Escrituras" (literal, moral, alegórico, anagógico) para ler o Hypnerotomachia Poliphili (AGAMBEN, 2014, p. 69): a glossolalia no Apóstolo Paulo e em Aristóteles é reencaminhada para uma releitura da poesia de Giovanni Pascoli (p. 93-94); a teoria do fragmento de Isidoro de Sevilha, mediada por Guido Cavalcanti e Dante, serve como contraste para analisar as Poesie della fine del mondo, de Antonio Delfini (p. 112); os Evangelhos são resgatados para dar conta do "contexto messiânico" envolvido no resgate que Andrea Zanzotto fez do termo grego erchomenos (p. 134). A enumeração de exemplos em Categorias italianas poderia continuar, mas parece mais relevante apontar o mesmo procedimento em Ideia da prosa (1982), em um fragmento no qual Agamben resgata o mesmo Delfini, agora em contato com Dino Campana, e ambos lidos a partir de Dante, da glossolalia e do provençal Folquet de Marselha (AGAMBEN, 2012, p. 42-44); e no ensaio Opus alchymicum, reunido no livro Il fuoco e il racconto, de 2014, em que Agamben faz uma leitura da poesia moderna - de Rimbaud a René Daumal - tentando ler o surrealismo como um itinerário espiritual que deve levar em conta a alquimia, a mística e o hermetismo da Antiguidade (AGAMBEN, 2014a, p. 126-129). Em outro registro, é possível lembrar o Fredric Jameson de O inconsciente politico (1981), que também resgata os níveis literal, moral, alegórico e anagógico do sentido em seu projeto de interpretação pós-estruturalista: "O sistema de quatro níveis ou sentidos é particularmente sugestivo na solução que oferece a um dilema interpretativo que em um mundo privatizado somos obrigados a viver muito mais intensamente do que o fizeram seus beneficiários alexandrinos e medievais: a saber, aquela incomensurabilidade a que nos referimos acima que paira entre o privado e o público, o psicológico e o social, o poético e o político" (JAMESON, 1992, p. 28). 
certo, aponta para muito além daquele alvo no qual a crítica moderna acreditou acertar" (AGAMBEN, 2014, p. 19). Para além também de uma tradicional classificação que levava em consideração estilos como a sátira, a mímica e a elegia, Dante estaria interessado em uma intensificação do contraste entre comédia e tragédia, acentuando, com isso, a distância de sua obra com relação à Eneida de Virgílio. A princípio, seguindo a carta a Cangrande, a comédia responderia ao esquema "início horrível" e "fim próspero", enquanto a tragédia funcionaria de maneira oposta, "início calmo" e "fim horrível" (AGAMBEN, 2014, p. 23). A questão, contudo, é mais ampla do que a definição do título dantesco, pois estabelece uma sorte de binarismo epistemológico que se mantém desde então, um não dito que talvez derive da "[...] nossa relutância em admitir que essas categorias, em cuja oposição a modernidade - de Hegel a Benjamin, de Goethe a Kierkegaard - projetou os seus mais profundos conflitos éticos, possam ter a sua origem remota na cultura medieval”. (AGAMBEN, 2014, p. 25)

Interessa aqui, portanto, buscar uma continuidade para esse fio argumentativo rapidamente apresentado por Agamben em seu ensaio - como a oposição "tragédia" e "comédia" segue operativa na modernidade e como se dá sua reconfiguração específica no âmbito da história das formas romanescas. São duas tradiçôes que levam essa oposição até Dante: de um lado, a leitura medieval da Poética de Aristóteles e, de outro, a paixão de Cristo e o surgimento do Novo Testamento. Dante realizou, na carta a Cangrande, "[...] a conjugação das categorias trágico/cômico com o tema da inocência e da culpa da criatura humana, em uma perspectiva na qual a tragédia aparece como a culpabilização do justo e a comédia como a justificação do culpado" (AGAMBEN, 2014, p. 26). O pecado original e a paixão de Cristo estão articulados na fundação de uma culpa "que se transmite independentemente da responsabilidade individual", mas é o segundo evento que permite a inversão do conflito "entre culpa natural e inocência pessoal na cisão entre inocência natural e culpa pessoal", alcançando a conclusão de que "a morte de Cristo liberta o homem da tragédia e torna possível a comédia” (AGAMBEN, 2014, p. 31-32). Por fim, Agamben apresenta a contraposição entre Dante como personagem "cômico", e Édipo como herói trágico: o primeiro "se purifica da culpa pessoal mostrando até o fim a sua vergonha", e 
o segundo que, "enquanto pessoalmente inocente, não pode nem confessar sua culpa nem aceitar a vergonha" (AGAMBEN, 2014, p. 36).

Em paralelo à questáo do título dantesco, Agamben reflete, como de hábito, sobre um contexto de reconfiguração conceitual e de indecibilidade ou oscilaçấo entre posiçôes aparentemente contraditórias, como é o caso aqui de "tragédia" e "comédia". Em termos narratológicos, o que está em questão na crítica dessa dicotomia é especialmente a determinação da natureza do início e do fim dos relatos (horrível ou calmo) como possibilidade de definição do trágico e do cômico. A potência da literatura, especialmente da literatura moderna, reside em sua capacidade de reposicionar intensidades e expectativas, confrontando perspectivas no interior do próprio texto e, com isso, tornando supérflua a definição essencialista do início e fim dos relatos. Ainda em Categorias italianas, por exemplo, em outro ensaio, no qual comenta Elsa Morante, Agamben fala de sua obra como estando "além tanto da tragédia quanto da comédia" (2014, p. 178). Fica aí estabelecido um nexo entre a argumentação prévia, que envolvia a definiçấo restrita desses dois campos e sua reconfiguração por parte de Dante, e o ponto de chegada que aqui será investigado especificamente - como a prosa narrativa dos últimos duzentos anos se movimenta nesse campo "além tanto da tragédia quanto da comédia".

\section{O romance de formação}

É com Mikhail Bakhtin que a reflexão sobre a prosa narrativa e a forma romanesca vai se apropriar do campo de indecidibilidade que contém o duplo movimento de atração e repulsa envolvendo tragédia e comédia. Em primeiro lugar, em Estética da criação verbal, Bakhtin analisa o Bildungsroman, o romance de formação (cujo exemplo maior é o Wilhelm Meister de Goethe), no qual "[...] o próprio herói e seu caráter se tornam uma grandeza variável na fórmula desse romance", e é precisamente essa variabilidade que torna supérfluo, mais uma vez, o essencialismo rígido dos "inícios calmos" e "finais horríveis", ou vice-versa (BAKHTIN, 2010, p. 219). Em seu trabalho sobre a estilística, dirá que "[...] todo romance, do ponto de vista da linguagem e da consciência linguística nele personificadas, é um híbrido", concluindo, mais adiante, que "[...] é provável que na lite- 
ratura universal não sejam poucas as obras de cujo caráter paródico sequer suspeitemos em nossos dias", ou seja, acentuando mais uma vez a instabilidade das categorias essencialistas quando se trata do discurso romanesco (BAKHTIN, 2015, p. 165, 177). Em Questóes de literatura e de estética, escreverá: "O gênero romanesco não dispóe de uma posição imanente", seja "no plano da forma", seja no plano "do gênero" (BAKHTIN, 2010a, p. 277). E, por fim, sabe-se que a leitura de Dostoiévski feita por Bakhtin, ao enfatizar o dialogismo, a carnavalização e a polifonia, esmiúça as diversas camadas heterogêneas do texto em constante confronto umas com as outras, sendo o campo de contato entre cômico e trágico não menos impuro ou híbrido: "[...] na evolução [...] da literatura europeia, a carnavalização ajudou constantemente a remover barreiras de toda espécie entre os gêneros, entre os sistemas herméticos de pensamento, entre diferentes estilos, etc, destruindo toda hermeticidade e o desconhecimento mútuo" (BAKHTIN, 2010b, p. 154).

Resgatando Bakhtin e comentando o mesmo Wilhelm Meister de Goethe, Franco Moretti, no prefácio que escreve vinte anos depois da primeira edição de seu livro sobre o Bildungsroman, The Way of the World, comenta indiretamente essa capacidade do discurso romanesco de reinventar e reconfigurar a natureza de certas cenas. $\mathrm{Na}$ cena final do romance de Goethe, Moretti diz que esperava ver, em sua primeira leitura, uma grande cena de resolução ou encaminhamento climático, mas que esse não é o caso - ou seja, o fim, assim como o começo, pode ser relatado como "calmo" ou "horrível" ao sabor da circunstância (MORETTI, 2000, p. v). "Perdi minha subjetividade, mas ganhei o mundo", é o que diz Goethe em sua Viagem à Itália, frase que Moretti captura como signo dessa oscilação da subjetividade que contribui para a transformação do discurso romanesco (MORETTI, 2000, p. vi). Da mesma forma que Dante serve a Agamben como ponto de clivagem na tradição e ponto de partida para uma releitura prospectiva da mesma tradiçáo, Goethe e seu uso particular do Bildungsroman servem a Bakhtin e seus continuadores, Moretti entre eles. Esses dois esforços de resgate e releitura se tocam e se complementam na medida em que o romance de formaçáo - por conta de sua heterogeneidade de registros discursivos e sua perspectivação oscilante - reitera a impossibilidade de determinar essencialmente 
os atributos seja do início, seja do fim do relato (recordemos que o célebre Prefácio a Cromwell, de Victor Hugo, é do mesmo ano em que Goethe escreve pela primeira vez o termo Weltliteratur ${ }^{2}$, 1827).

Rodolphe Gasché já mostrou que o procedimento não estava restrito nem ao romance de formação, nem à prática de Goethe, sendo presente e central na obra de um rigoroso contemporâneo seu, Georg Wilhelm Friedrich Hegel. Confrontando a Estética de Hegel com sua Fenomenologia do Espirito, Gasché fala de uma "autodissolução da seriedade" e de como dialeticamente elementos da teoria do cômico são reconfigurados no desenvolvimento hegeliano do conceito de trágico - a falta de limites de um registro tornando possível o sistema rígido de limites do outro (GASCHÉ, 2000, p. 37-56). Por essa perspectiva, a conhecida declaração de Jean Hyppolite, em seu livro Gênese e estruturada da Fenomenologia do Espirito de Hegel, em que fala do projeto de Hegel justamente como um romance de formação, um Bildungsroman (cujo herói é precisamente o "Espírito" que luta para atravessar a história da consciência), ganha peso e relevância (HYPPOLITE, 1979, p. 11-12)³. Apesar da tentativa de conferir um caráter absoluto ao Espírito, a própria constituiçáo nar-

2 Victor Hugo assina o Prefácio em outubro de 1827 e nele advoga justamente pela mescla dos registros "alto" e "baixo", que denomina "sublime" e "grotesco": "O sublime sobre o sublime dificilmente produz um contraste, e tem-se necessidade de descansar de tudo, até do belo. Parece, ao contrário, que o grotesco é um tempo de parada, um termo de comparação, um ponto de partida, de onde nos elevamos para o belo com uma percepçáo mais fresca e mais excitada" (HUGO, 2007, p. 33). Sobre Goethe, escreve George Steiner: "Weltliteratur ('literatura mundial') é uma palavra criada por Goethe. Nós a encontramos pela primeira vez em um diário datado de 15 de janeiro de 1827. Mas o conceito e sua prática permeiam toda a vida de Goethe, que traduziu textos de dezoito línguas, dentre as quais o gaulês, o árabe, o chinês, o hebraico, o persa e o finlandês (na verdade, muitas dessas traduções foram indiretas e de segunda mão)" (STEINER, 2001, p. 154). Erich Auerbach, na sua Introdução aos estudos literários, escrita em 1943 na Turquia, enfatiza a preponderância de Victor Hugo nesse contexto: "O princípio estético que está na base do Realismo moderno já tinha sido proclamado por Victor Hugo e seu grupo, por volta de 1830, um pouco antes da publicação dos primeiros romances realistas: é o princípio da mistura de gêneros, que permite tratar de maneira séria e mesmo trágica a realidade cotidiana, em toda a extensão de seus problemas humanos, sociais, políticos, econômicos, psicológicos; princípio que a estética clássica condenava, separando claramente o estilo elevado e o conceito do trágico de todo contato com a realidade ordinária da vida presente" (AUERBACH, 2015, p. 368).

3 O trabalho de Stefan Andriopoulos em parte se aproxima desse esforço de reposicionar a obra de Hegel diante de experiências epistemológicas diversas, como é o caso em seu contato com a tradição literária, por exemplo. Em Apariçōes espectrais: $o$ idealismo alemão, o romance gótico e a mídia óptica, Andriopolous aproxima Hegel não da tradição do 
rativa de seu percurso, sob a égide do Bildungsroman, de seu contexto histórico imediato e das releituras posteriores, reforça a perspectiva do não essencialismo e da instabilidade das categorias. Assim como a divisão entre comédia e tragédia torna-se insustentável na emergência específica do romance de formação, essa instabilidade restrita (comédia e tragédia, o fim calmo ou horrível) também se encaminha para uma instabilidade mais geral, um hibridismo ou heterogeneidade típicas do discurso romanesco, como apontou Bakhtin. Ao passar de Goethe a Dostoiévski, é também Bakhtin quem marca a ampliação desse registro de instabilidade de categorias para além do romance de formação, marcando, como se sabe, o discurso como campo de luta constante, e a língua como "ideologicamente saturada" (BAKHTIN, 2010a, p. 77).

\section{Em busca do tempo perdido}

Gérard Genette, em Figuras III, permite acrescentar um terceiro termo a esse percurso de investigação: de Goethe a Dostoiévski, e agora a Marcel Proust (o que permite que essa retrospectiva opere a partir de um ciclo aproximado de 60 anos: o Wilhelm Meister de

Bildungsroman, mas do romance gótico: "Segundo Hegel, o devir do espírito absoluto depende de uma anagnose em que o espírito absoluto se reconheça em suas formas anteriores. Essa superação final da diferença pressupóe uma temporalidade externa em que o espírito tenha-se manifestado em várias formas. Hegel caracteriza essa 'história' do espírito, seu movimento do espírito subjetivo para o objetivo e o absoluto, como 'um movimento lento e uma sucessão de espíritos, uma galeria de imagens em que cada um [é] dotado de todas as riquezas do espírito'. As páginas finais da Fenomenologia evocam, portanto, a sucessão de imagens em movimento numa fantasmagoria, bem como o tropo do herói do romance gótico fitando numa galeria de retratos de ancestrais num castelo medieval. [...] Outro ponto de referência da 'galeria de imagens' descrita no final da Fenomenologia é o romance gótico contemporâneo. $\mathrm{O}$ interesse narrativo desse gênero literário centrava-se na restauração da sucessão genealógica legítima, muitas vezes confrontando um protagonista com uma galeria de retratos de ancestrais" (ANDRIOPOULOS, 2014, p. 72-73). Em seu livro Romance das origens, origens do romance, no capítulo significativamente intitulado "A busca do absoluto", Marthe Robert, ainda que não citando diretamente Hegel, atravessa de forma oblíqua esse campo da legitimidade do Espírito ao falar de uma figura muito próxima ao filósofo, outro de seus principais contemporâneos, Napoleão. Se de um lado encontramos a legitimidade, do outro está a bastardia: “[...] a trajetória do Bastardo no século da História do romance é propriamente inconcebível sem a escalada de Napoleáo [...] Napoleáo é romance de ponta a ponta, um romance que se faz à medida que ele influencia os acontecimentos da história e que, pela primeira vez na época moderna, é impresso em letras de carne e sangue no próprio tecido da realidade" (ROBERT, 2007, p. 179). 
Goethe, 1795-1796; Crime e castigo, de Dostoiévski, 1866; e a Recherche de Proust, interrompida em 1922 com sua morte, mas que teve o último volume publicado em 1927). Da mesma forma que Agamben com Dante e Bakhtin com Goethe, Genette percebe em Proust uma reconfiguração dos elementos então disponíveis no campo literário - ecoando, até certo ponto, a ideia de Walter Benjamin de que Proust tanto inauguraria quanto encerraria um gênero por si só (BENJAMIN, 1994, p. 36). Em determinado momento de seu comentário a Proust, Genette absorve não apenas a tradição do romance de formação, mas também a figura de Hegel:

O assunto de Em busca do tempo perdido é mesmo "Marcel se torna escritor", não "Marcel escritor": a Busca permanece um romance de formação, e seria falsificar suas intençóes e, sobretudo, forçar seu sentido querer ver um "romance do romancista", como nos Moedeiros falsos; trata-se de um romance do futuro romancista. "A continuação", dizia Hegel a respeito, justamente, do Bildungsroman, "não tem mais nada de romanesco..."; é provável que Proust aplicasse essa fórmula à sua própria narrativa: o romanesco é a procura, é a busca, que termina em achado (a revelação), náo o emprego que será feito posteriormente desse achado. A descoberta final da verdade, o encontro tardio da vocação, como a felicidade dos amantes reunidos, pode ser um desenlace, mas não uma etapa; e nesse sentido, o assunto da Busca é de fato um assunto tradicional. A narrativa deve, portanto, interromper-se antes que o herói encontre o narrador, não convém que escrevam juntos a palavra: Fim. A última frase deste segundo personagem é quando - é que - o primeiro chegou, enfim, à sua primeira. A distância entre o fim da história e o momento da narração é, pois, o tempo necessário para o herói escrever este livro, que é e não é aquele que o narrador, por sua vez, nos revela no espaço de um relâmpago. (GENETTE, 2017, p. 304).

Significativamente, a leitura de Genette também passa por uma consideração acerca do fim do relato, fim este que, na obra Em busca do tempo perdido, só é alcançado para remeter mais uma vez ao início. $\mathrm{O}$ uso do tempo em Proust já não é progressivo, acumulativo ou cronológico, sendo a principal prova disso esse momento de en- 
cerramento destacado por Genette, no qual o sentido tradicional de fim permanece em suspenso, em dívida. A "formação" envolvida no romance de Proust é a "formação do romancista" ou, ainda, a formação da possibilidade da própria escritura. Retornando à elaboração de Franco Moretti em torno do romance de formaçáo, podemos apreciar de forma mais detalhada esse procedimento de Proust destacado por Genette. Citando a Fenomenologia do Espírito de Hegel, o trecho no qual o filósofo liga o Absoluto à resoluçáo e ao final, Moretti afirma que, no romance de formaçáo tradicional, o "final feliz" representa o "triunfo do significado sobre o tempo": "o único propósito do tempo é nos levar ao final, permitindo a epifania de uma essência”, e, tornado supérfluo, o "tempo abandona o palco para dar lugar à dança harmoniosa da Verdade com o Todo" (MORETTI, 2000, p. 55). Diante disso, fica clara a importância da decisiva reconfiguração proposta por Proust: ao recusar a resolução definitiva, recusa também a "epifania de uma essência", fazendo da busca o motivo central da escritura, e não mais a resolução (o tempo, dessa forma, permanecendo sempre no "palco", enfileirando, dialética e paradoxalmente, uma série de epifania - e não mais uma única, endereçada ao Absoluto, à Verdade ou ao Todo de que fala Hegel $)^{4}$.

"O totem do totum não existe mais", escreve Franco Rella a partir de Adorno, mas em um livro dedicado a pensar a relação entre Marcel Proust e Franz Kafka, Scritture estreme (RELLA, 2005, p. 45). Toda a argumentação de Rella ao longo de seu livro está baseada no projeto inacabado de Walter Benjamin de dedicar um ensaio à comparação das obras de Proust e Kafka - projeto que, mesmo não ganhando forma definitiva, se espalha ao longo da obra de Benjamin como um todo, especialmente no Livro das Passagens (RELLA, 2005,

4 É preciso frisar também a relevância desse termo escolhido por Genette para o fechamento da citação em questão, relâmpago, tendo em mente a posição de destaque dessa metáfora na obra de Walter Benjamin, contemporâneo e tradutor de Marcel Proust. Na quinta tese sobre o conceito de história, Benjamin fala da "verdadeira imagem do passado" que "passa célere e furtiva", no "tempo de um relâmpago", segundo o comentário de Michael Löwy, que completa sua glosa apontando o fato de Benjamin mencionar justamente Dante em uma das variantes do texto: "a versão francesa redigida por Benjamin se distingue por uma referência a Dante: 'A verdade imóvel, que só espera o pesquisador, não corresponde de maneira alguma ao conceito de verdade em matéria de história. Ela se apoia muito mais no verso de Dante que diz: Trata-se de uma imagem única, insubstituível, do passado, que se esvaiu com cada presente que não soube se reconhecer visado por ela" (LÖWY, 2005, p. 62). 
p. 12). Rella busca ampliar as intuiçóes benjaminianas, organizando metodicamente - em um livro que se organiza a partir de fragmentos críticos, numerados até 100 - os pontos possíveis de contato e afastamento entre Proust e Kafka. Ainda que parta de uma visão clara acerca das diferenças de abordagem formal dos dois autores - o fluxo caudaloso da Recherche de Proust de um lado, os fragmentos concisos, as fábulas e alegorias de Kafka de outro -, Rella ressalta a questão do tempo em dois aspectos centrais, a busca e a suspensão, que se reúnem na ideia-síntese da morte. A obra de Proust, segundo Rella, apresenta a "construção lenta, fatigosa, mas ao fim vitoriosa, de um poder-morrer", uma sorte de "direito à morte", "conquistado depois de atravessar a zona das perversóes sexuais e sentimentais, as zonas do inumano"; do lado de Kafka, "sua necessidade de escritura" leva a "uma luta contra o poder, uma luta tão desesperada e extrema que se conclui com a destruição não dos poderes, inexpugnáveis, mas do único poder que resta o sujeito único: o poder morrer" (RELLA, 2005, p. 134). Em outras palavras, um "poder morrer" que, na condição de fim extremo e definitivo, é continuamente encenado na escritura, dissolvendo, com isso, sua essencialidade, sua centralidade, sua condição de "totem do totum".

Maurice Blanchot, em De Kafka à Kafka, contrapóe a K., o protagonista de $O$ Castelo, figura do exílio e da obstinação com o exílio, a inércia de Joseph K., que crê ainda pertencer a este mundo, e também crê que "o processo possa ser vencido ou perdido aqui" (BLANCHOT, 1981, p. 94). Por essa crença, o percurso dos dois romances é distinto. O protagonista de $O$ processo, escreve Blanchot, "na sua negligência, na sua indiferença, e na satisfação de um homem provido de boa situação social, não se dá conta de ter sido posto para fora da existência" (BLANCHOT, 1981, p. 114). Tendo se dado conta, teria seguido a via de K., a via do Castelo, que conduz ao espaço intermediário entre vida e morte (como no conto do caçador Gracchus, por exemplo5). Mas é também, de certa forma, essa a via seguida

5 É possível apontar aqui em direção a outro ensaio de Giorgio Agamben em Categorias italianas, intitulado "A caça da língua", também este um resgate de Dante. A perspectiva adotada - o resgate do caçador e construtor bíblico Nemrod na Comédia - pode servir também para uma leitura de "O caçador Gracchus", o conto de Kafka. A caça de Nemrod, segundo Dante, é “contra Deus”, qualificação que permanece não desenvolvida e que será retomada por Agamben: "se a punição de Babel foi a confusão das línguas, é provável que 
por Joseph K. Se é verdade que o K. do Castelo é o mesmo Kafka que escreve a Felice, como afirma Elias Canetti em $O$ outro processo (1988), da sua absoluta extraterritorialidade, exílio e distanciamento, também é verdade que Joseph K. se faz ver e comunicar através de uma distância - a distância de outro espaço intermediário, aquele que articula sono e vigília (como em $A$ metamorfose, por exemplo). Esse instante expandido e quase que fora do tempo abarca não só sua abrupta captura, mas também seu sacrifício final, o "poder morrer" de que fala Franco Rella.

A dimensão do fim - que já não pode ser simplesmente calmo ou horrível - é reconfigurada na medida em que a própria tradição do romance de formação - que já carregava consigo uma problematização das categorias de trágico e cômico - é rearmada através do motivo da "busca" na Recherche de Proust. Contemporâneos de Proust, contudo, alargam a questão para além do escopo do romance de formação - sendo digno de nota que essa expansão da perspectiva se dê, em primeiro lugar, a partir de Kafka e, em viés crítico, a partir do esforço comparatista de Walter Benjamin, conforme resgatado por Franco Rella. Benjamin, no Livro das Passagens, tenta definir a relação entre contrários sempre a partir da ambivalência, da oscilação: "o conceito de progresso deve estar fundado na ideia de catástrofe" (BENJAMIN, 2002, p. 473) e "superar a noção de 'progresso' e superar a noção de 'período de decadência' são dois lados de uma coisa só" (460). Nesse contexto, pode-se resgatar a epígrafe da introdução de 1939 de Benjamin ao projeto das passagens, retirada da obra de fôlego de Maxime du Camp em seis volumes, Paris, ses organes, ses fonctions, sa vie (1869-1875): "a História é como Jano, tem duas faces. Olhando

a caça de Nemrod tivesse a ver com um aperfeiçoamento artificial da única língua dos homens, que devia abrir à razáo um poder sem limites" (AGAMBEN, 2014, p. 193). Em seguida, Agamben mostra como, em De vulgari Eloquentia, Dante fala da pesquisa da língua como uma caça e de que esse "risco" permanece operativo ainda hoje: "todo sério empenho humano na palavra deve sempre se confrontar com esse risco" (AGAMBEN, 2014, p. 194). Dentro desse campo da dimensão venatória da linguagem e da investigação acerca da linguagem, é possível relembrar o extensamente comentado ensaio de Carlo Ginzburg, "Sinais: raízes de um paradigma indiciário", no qual fala de "um saber de tipo venatório" e do caçador como "o primeiro a 'narrar uma história' porque era o único capaz de ler, nas pistas mudas (se não imperceptíveis) deixadas pela presa, uma série coerente de eventos" (GINZBURG, 1989, p. 152). 
o passado ou o presente, vê as mesmas coisas" (BENJAMIN, 2002, p. 14).

\section{Conclusão: tempo e processo}

Nesse ponto, chegamos aos "profundos conflitos éticos" de que fala Agamben no ensaio "Comédia", nos quais se envolve "a modernidade - de Hegel a Benjamin, de Goethe a Kierkegaard" (AGAMBEN, 2014, p. 25). Os três primeiros nomes foram aqui contemplados no viés específico da forma romanesca, com o acréscimo final de Franz Kafka. O movimento decisivo nessa modernidade de que fala Agamben é a transformação que se opera na relação entre o tempo do relato e o tempo da história, não mais coesos ou lineares, operando em regime de espelhamento, mas atravessados, comprometidos mutuamente. Essa instabilidade de posiçôes entre sujeito e mundo opera, em Proust e Kafka, segundo Franco Rella, a partir de uma performance dúplice da escritura, como doença e como testemunho (RELLA, 2005, p. 26). É a partir dessa última categoria que Giorgio Agamben retoma Kafka, em O que resta de Auschwitz, quando conta que, em 1983, "o editor Einaudi pediu a [Primo] Levi que traduzisse $O$ processo, de Kafka”. Raramente, continua Agamben:

[...] se observou que esse livro, no qual a lei se apresenta unicamente na forma do processo, traz uma intuição profunda sobre a natureza do direito, que aqui não se apresenta - segundo a opiniáo comum - tanto como norma, quanto como julgamento e, portanto, processo. Ora, se a essência da lei - de toda lei - é o processo, se todo direito é unicamente direito processual, então execução e transgressão, inocência e culpabilidade, obediência e desobediência se confundem e perdem importância. [...]. O julgamento é em si mesmo a finalidade, e isso - já foi dito - constitui o seu mistério, o mistério do processo (AGAMBEN, 2008, p. 28).

Não é apenas em $O$ processo que Kafka reflete sobre isso que a finalidade do processo é gerar o processo. Isso está, por exemplo, em $A$ construção, conto no qual o ser envolvido na "construção", por mais que indique finalidades paralelas (exercício, estoque de comida), 
apenas com o intuito de realizar a construção (KAFKA, 1998, p. 70). Em O que resta de Auschwitz, Agamben resgata Salvatore Satta e seu Il mistero del processo, buscando aí conclusões acerca da poética de Kafka: "Isso significa também que 'a sentença de absolvição é a confissão de um erro judicial', que 'cada um é intimamente inocente', mas que o único verdadeiro inocente 'não é quem acaba sendo absolvido, e sim quem passa pela vida sem julgamento”. (AGAMBEN, 2008, p. 29). O "mistério do processo", que alcança tanto Kafka quanto Salvatore Satta (citado por Agamben como jurista, mas autor também ele de um romance dedicado à reflexão sobre o tempo, Il giorno del giudizio, lançado postumamente em 1977), carrega consigo aquela carga ambivalente, entre o julgamento e a culpabilidade, que Agamben já havia rastreado em Dante - mas apontando, porém, para a noção de "pecado" compartilhada pela Poética de Aristóteles e pelo Novo Testamento através da sobrevivência e tradução do termo grego hamartía (AGAMBEN, 2014, p. 26-27).

A aproximação direta entre os dilemas éticos da modernidade e as categorias tradicionais da teoria literária, que Agamben somente anuncia no ensaio "Comédia", é feita em O que resta de Auschwitz, especialmente no ponto em que mais uma vez Hegel é resgatado, e a pretensão "de apresentar a vergonha do sobrevivente como um conflito trágico" é recusada (AGAMBEN, 2008, p. 101). É preciso ter em mente também que a dimensão da "vergonha" é central no ensaio sobre Dante. "A teoria da vergonha - que Dante desenvolve no canto XXXI do Purgatório - é o fulcro em torno do qual se cumpre esse giro da culpa natural trágica a uma culpa pessoal cômica" (AGAMBEN, 2014, p. 35), assim como é central na argumentação de $O$ que resta de Auschwitz, que pode encarado como um livro no qual Agamben apresenta uma chave de leitura possível para a literatura do século XX. A partir de Lévinas, mas depois de passar por Primo Levi e Franz Kafka (e preparando o terreno para alcançar Fernando Pessoa e Giorgio Manganelli), Agamben escreve: "a vergonha não deriva, como acontece na doutrina dos moralistas, da consciência de uma imperfeição ou de uma carência do nosso ser frente à qual tomamos distância”, pelo contrário - continua o autor - “[...] ela fundamenta-se na impossibilidade do nosso ser de dessolidarizar-se de 
si mesmo, na sua absoluta incapacidade de romper consigo próprio" (AGAMBEN, 2008, p. 109).

Se fizer sentido apontar a falência das categorias essencialistas de "tragédia" e "comédia" no âmbito do romance de formação, o percurso feito até aqui leva à conclusão de que o discurso da formação (da Bildung, da educação, da forma, da imagem do mundo no sujeito e do sujeito no mundo) é também reconfigurado diante da falência das categorias essencialistas de "sujeito" e "mundo". Em Proust, Kafka ou Fernando Pessoa, “[...] o sujeito não tem outro conteúdo senão a própria dessubjetivação, convertendo-se em testemunha do próprio desconcerto, da própria perda de si como sujeito" (AGAMBEN, 2008, p. 110). Esse contínuo arranjo e rearranjo das posiçóes do sujeito no texto e no mundo será preocupaçáo central para a ficção e sua teoria (de Augusto Monterroso a Jacques Derrida, por exemplo ${ }^{6}$ ), bem como uma tarefa que se anuncia - ao menos desde Dante - para a crítica do presente.

\section{Referências bibliográficas}

AGAMBEN, Giorgio. Categorias italianas: estudos de poética e literatura. Trad. Carlos Capela, Vinícius Honesko. Florianópolis: Editora da UFSC, 2014. . Il fuoco e il racconto. Roma: Nottetempo, 2014a.

6 Em um dos fragmentos reunidos em Movimiento perpetuo, de 1972, intitulado "A escolher", Augusto Monterroso escreve: "Os dois maiores humoristas que conhecemos são Kafka e Borges. 'A loteria em Babilônia' e $O$ processo são regozijos do começo ao fim. Lembre que Max Brod conta que quando Kafka lia passagens desse romance Kafka quase se atirava no chão de rir com o que acontecia ao senhor K. Mesmo assim, o efeito que o livro produz é trágico. Também é oportuno recordar o que aconteceu com o Quixote: seus primeiros leitores riam; os românticos começaram a chorar lendo, exceto os eruditos, como Don Diego Clemencín, que gostava muito quando por acaso encontrava uma frase correta em Cervantes; e os modernos nem riem nem choram com ele, e talvez façam bem" (MONTERROSO, 1990, p. 135). Jacques Derrida, por sua vez, em $O$ monolinguismo do outro, de 1996, fala do Bildungsroman de forma ambivalente, ao falar de seu próprio projeto no livro em questão: "Encore un mot pour épiloguer un peu. Ce que j'ébauche ici, ce n'est surtout pas le commencement d'une esquisse d'autobiographie ou d'anamnèse, pas même un timide essai de Bildungsroman intellectuel. Plutôt que l'exposition de moi, ce serait l'exposé de ce qui aura fait obstacle, pour moi, à cette auto-exposition. De ce qui m'aura exposé, donc, à cet obstacle, et jeté contre lui. Ce grave accident de circulation auquel je ne cesse de penser" (DERRIDA, 1996, p. 131). 
AGAMBEN, Giorgio. Ideia da prosa. Trad. João Barrento. Belo Horizonte: Autêntica Editora, 2012.

- O que resta de Auschwitz: o arquivo e a testemunha (Homo Sacer III). Trad. Selvino Assmann. São Paulo: Boitempo, 2008.

ANDRIOPOULOS, Stefan. Apariçóes espectrais: o idealismo alemão, o romance gótico e a mídia óptica. Trad. Vera Ribeiro. Rio de Janeiro: Contraponto, 2014.

AUERBACH, Erich. Introdução aos estudos literários. Trad. José Paulo Paes. São Paulo: Cosac Naify, 2015.

BAKHTIN, Mikhail. Teoria do romance I: a estilística. Trad. Paulo Bezerra. São Paulo: Editora 34, 2015.

. Trad. Paulo Bezerra. São Paulo: Editora WMF Martins Fontes, 2010.

- Questóes de literatura e de estética: a teoria do romance. 10a ed. Trad. Aurora Fornoni Bernadini et al. São Paulo: Hucitec Editora, 2010a.

- Problemas da poética de Dostoiévski. $5^{\mathrm{a}}$ ed. Trad. Paulo Bezerra. Rio de Janeiro: Forense Universitária, 2010b.

- Obras escolhidas I: magia e técnica, arte e política: ensaios sobre literatura e história da cultura. Trad. Sérgio Paulo Rouanet; prefácio Jeanne Marie Gagnebin. São Paulo: Brasiliense, 1994.

BENJAMIN, Walter. The Arcades Project. Translated by Howard Eiland and Kevin McLaughlin; prepared on the basis of the Gennan volume edited by Rolf Tiedemann. Cambridge, Mass.: Harvard University Press, 2002.

BLANCHOT, Maurice. De Kafka à Kafka. Paris: Gallimard, 1981.

CANETTI, Elias. O outro processo: as cartas de Kafka a Felice. Trad. Herbert Caro. Rio de Janeiro: Espaço e Tempo, 1988.

DERRIDA, Jacques. Le monolinguisme de l'autre ou la prothèse d'origine. Paris: Galilée, 1996.

GASCHÉ, Rodolphe. Self-Dissolving Seriousness: On the Comic in the Hegelian Conception of Tragedy. In: BEISTEGUI, Miguel; SPARKS, Simon (Org.). Philosophy and Tragedy. Nova York: Routledge, 2000, p. 37-56.

GENETTE, Gérard. Figuras III. Trad. Ana Alencar. São Paulo: Estação Liberdade, 2017.

GINZBURG, Carlo. Mitos, emblemas, sinais. Trad. Federico Carotti. São Paulo: Companhia das Letras, 1989. 
HUGO, Victor. Do grotesco e do sublime: tradução do Prefácio de Cromwell.

Trad. Célia Berrettini. São Paulo: Perspectiva, 2007.

HYPPOLITE, Jean. Genesis and Structure of Hegel's "Phenomenology of Spirit". Traduzido do francês ao inglês por John Heckman e Samuel Cherniak. Evanston, Illinois: Northwestern University Press, 1979.

JAMESON, Fredric. O inconsciente politico: a narrativa como ato socialmente simbólico. Trad. Valter Lellis Siqueira. São Paulo: Editora Ática, 1992.

KAFKA, Franz. Um artista da fome e A construção. Trad. Modesto Carone. São Paulo: Companhia das Letras, 1998.

LÖWY, Michael. Walter Benjamin: aviso de incêndio - uma leitura das teses "Sobre o conceito de história". Trad. Wanda Nogueira Caldeira Brandt. Tradução das teses: Jeanne Marie Gagnebin, Marcos Lutz Müller. São Paulo: Boitempo, 2005.

MONTERROSO, Augusto. Movimiento perpetuo. Barcelona: Anagrama, 1990.

MORETTI, Franco. The Way of the World: The Bildungsroman in European Culture. Traduzido do italiano ao inglês por Albert Sbragia. Nova York: Verso, 2000.

RELLA, Franco. Scritture estreme: Proust e Kafka. Milão: Feltrinelli, 2005.

ROBERT, Marthe. Romance das origens, origens do romance. Trad. André Telles. São Paulo: Cosac Naify, 2007.

STEINER, George. Nenhuma paixão desperdiçada. Trad. Maria Alice Máximo. Rio de Janeiro: Record, 2001.

Kelvin Falcáo Klein é graduado em Comunicação Social pela Escola de Comunicação e Artes do Centro Universitário da Cidade do Rio de Janeiro, Mestre em Literatura Comparada, pela Universidade Federal do Rio Grande do Sul (UFRS), e Doutor em Teoria Literária pela Universidade Federal de Santa Catarina (UFSC). É professor Adjunto de Literatura Comparada na Escola de Letras da Universidade Federal do Estado do Rio de Janeiro (UNIRIO), atuando também no Programa de Pós-Graduação em História da mesma instituição. Atua sobretudo na área da Literatura Comparada, Teoria Literária, Crítica Literária e Prosa Contemporânea. Autor dos livros Conversas apócrifas com Enrique Vila-Matas (2011) e Wilcock, fiç̧áo e arquivo (2018). E-mail: kelvin.klein@gmail.com

Recebido em: 16/01/2018

Aceito em: 15/07/2018 